\title{
Usefulness of a mobile app to improve performance of specialists in responding correctly to CRC screening and surveillance clinical scenarios
}

\section{(ㄷ)(우우}

Authors

Lisandro Pereyra', Leandro Steinberg², Juan M. Criniti ${ }^{3}$, Pablo Luna1, Rafael Escobar ${ }^{4}$, Maximiliano Bun¹, Martín Yantorno $^{5}$, Sebastian Esteves ${ }^{6}$, Nicolas Gonzalez ${ }^{7}$, Pablo Hoffman ${ }^{8}$, Mariano Marcolongo ${ }^{9}$, Gastón Jury ${ }^{10}$, Javier Topor $^{11}$, Félix Trelles ${ }^{12}$, Cristina Nazar ${ }^{13}$, Vitor N. Arantes ${ }^{14}$

Institutions

1 Endoscopy Unit, Hospital Alemán, Buenos Aires, Argentina

2 Gastroenterology Department, Fundación Favaloro, Buenos Aires, Argentina

3 Internal Medicine Department, Hospital Alemán, Buenos Aires, Argentina

4 Gastroenterology Department, Sanatorio Mendez, Buenos Aires, Argentina

5 Gastroenterology Department, General San Martín, La Plata, Argentina

6 Gastroenterology and Endoscopy Department, Clínica Cmic, Neuquén, Argentina

7 Gastroenterology Department, Hospital Británico Montevideo, Uruguay

8 Gastroenterology Unit, Gedyt, Buenos Aires, Argentina

9 Gastroenterology and Endoscopy Department, Hospital Italiano, Buenos Aires Argentina

10 Gastroenterology Unit, Centro de Estudios Digestivos, Mar Del Plata, Argentina

11 Gastroenterology Department, Sanatorio Mater Dei, Buenos Aires, Argentina

12 Gastroenterology Department, Hospital Durand, Buenos Aires, Argentina

13 Gastroenterology Department, Hospital Bonorino Udaondo, Buenos Aires, Argentina

14 Endoscopy Unit, Clinics Hospital, Federal University of Minas Gerais, Brasil

submitted 3.2.2021

accepted after revision 8.6 .2021

Bibliography

Endosc Int Open 2021; 09: E1640-E1648

DOI 10.1055/a-1544-4773

ISSN 2364-3722

(C) 2021. The Author(s).

This is an open access article published by Thieme under the terms of the Creative Commons Attribution-NonDerivative-NonCommercial License, permitting copying and reproduction so long as the original work is given appropriate credit. Contents

\author{
may not be used for commercial purposes, or adapted, remixed, transformed or \\ built upon. (https://creativecommons.org/licenses/by-nc-nd/4.0/) \\ Georg Thieme Verlag KG, Rüdigerstraße 14, \\ 70469 Stuttgart, Germany \\ Corresponding author \\ Lisandro Pereyra, Av. Pueyrredón 1640, Buenos Aires, \\ Argentina \\ lisandro_pereyra@hotmail.com
}

\section{ABSTRACT}

Background and study aims The adherence to and knowledge of physicians about colorectal cancer (CRC) screening and surveillance guidelines is still suboptimal, threatening the effectiveness of CRC screening. This study assessed the usefulness of a mobile decision support system (MDSS) to improve physician ability to recommend proper timing of and intervals for CRC screening and surveillance.

Patients and methods This was a binational, single-blinded, randomized clinical trial including gastroenterologists and colorectal surgeons from Argentina and Uruguay. The specialists were invited to respond to a questionnaire with 10 CRC screening and surveillance clinical scenarios, randomized into two groups, with and without access to a dedicated app (CaPtyVa). The main outcome measure was the proportion of physicians correctly solving at least $60 \%$ of the clinical cases according to local guidelines.

Results A total of 213 physicians were included. The proportion of physicians responding correctly at least $60 \%$ of the vignettes was higher in the app group as compared to the control group ( $90 \%$ versus $56 \%$ ) (relative risk [RR] 1.6 $95 \%$ confidence interval $[\mathrm{Cl}]$ 1.34-1.91). The performance was also higher in the app group for both vignette categories: CRC screening ( $93 \%$ vs $75 \%$ RR 1.24, $95 \% \mathrm{Cl} 1.01-1.40$ ) and surveillance ( $85 \%$ vs $47 \%$ RR $1.8195 \% \mathrm{Cl} 1.46-2.22$ ), respectively. Physicians considered the app easy to use and of great utility in daily practice. 
Conclusions A MDSS was shown to be a useful tool that improved specialist performance in solving CRC screening and surveillance clinical scenarios. Its implementation in daily practice may facilitate the adherence of physicians to CRC screening and surveillance guidelines.

\section{Introduction}

Proper implementation of guidelines has the potential to improve health care quality and reduce costs by promoting the use of evidence-based interventions [1-3]. However, these benefits vary significantly, based largely on the way guidelines are applied in clinical practice. Physician adherence to guidelines is a determining factor in their successful implementation [4]. It has been suggested that physicians have difficulties in memorizing and processing the complex information contained in some guidelines.

Computer-based clinical decision support systems (CDSSs) are defined as "any software designed to aid in clinical decision-making in which characteristics of individual patients are matched to a computerized knowledge base for the purpose of generating patient-specific assessment or recommendations, that are then presented to clinicians for consideration" [5]. As a result of the reported suboptimal evidence-based health care delivered and its critical consequences for patient health outcomes [6-8], different health care organizations have been promoting CDSSs, aiming to improve care delivery [9]. These systems have been shown to facilitate prescribing practices, reduce medication errors, enhance the delivery of preventive care services, and improve adherence to clinical guidelines [10-15].

Taking into account the global use of cell phones, the development of technologies and software integrated into a standard mobile app independent of personal computers could provide an effective approach i to allow these decision support systems to be implemented into other clinical information systems, such as a mobile decision support system (MDSS) [1618].

Colorectal cancer (CRC) is a major global medical and public health challenge, accounting for 881.000 deaths annually [19]. Evidence-based CRC screening strategies have shown to be effective in reducing CRC mortality. Hence, the majority of CRC deaths are believed to be the result of CRC screening process breakdowns [20]. Multiple studies report overuse and underuse of colonoscopy, as well as poor physician knowledge about and adherence to CRC screening guidelines, impairing their ability to apply the guidelines in clinical practice. All these factors may threaten the effectiveness of CRC screening programs.

Therefore, we developed a mobile-based ap,p named CaPtyVa CCR, that could be useful for physicians to improve CRC screening and surveillance guideline-based decision-making [21].

The aim of this prospective study was to evaluate whether this app improved the performance of specialists in gastroenterology and colorectal surgery in addressing CRC screening and surveillance clinical scenarios according to current guidelines.

\section{Patients and methods}

\section{Study design}

A prospective, binational, single-blinded, randomized study was conducted between May and June 2020. A 10-question online survey was created with CRC screening and surveillance clinical cases reflecting real-life daily practice scenarios. After the questions were developed, they were pretested and discussed for content and clarity by three board-certified gastroenterologists with more than 10 years' experience in practice ( Fig.1). Gastroenterologists and colorectal surgeons who were members of four medical societies from Argentina and Uruguay-Endoscopistas de Buenos Aires (ENDIBA), Federación Argentina de Endoscopía Digestiva, Sociedad Argentina de Coloproctología (SACP), and Sociedad Uruguaya de Endoscopía Digestiva-were randomly selected and invited by email to participate in this study and to answer the online questionnaire. One additional reminder email was sent 1 week later to increase the response rate. Only physicians who responded to the email and consented to enter the study were randomized and included in the trial. All participants were asked to complete a digital informed consent explaining the purpose of the study, the inclusion and exclusion criteria, and investigator and participant responsibilities.

The study was approved by the Institutional Review Board and Ethics Committee of the Hospital Alemán, Buenos Aires Argentina (2632 V4). The study was also registered at Clinical Trials (NCTNCT04389502).

\section{Assignments and blinding}

The specialists included in the study were randomly allocated in a 1:1 ratio using a random numbers sequence created with $\mathrm{Mi}$ crosoft Excel (Microsoft Corp.2016. Redmond, Washington, United States) (central randomization). Randomization and allocation were performed by an investigator who was blinded to physician specialty, experience, CRC screening guideline knowledge, and endoscopy practice status. The participants were divided into two groups: 1 . control group (asked to complete the questionnaire based on their current knowledge or in the same way they did it in daily practice); and 2 . intervention group (received a version of the app and a tutorial video and were asked to complete the questionnaire using the dedicated app).

Investigators were blinded to treatment allocation throughout the study until planned statistical analysis was finished. All authors had access to the study data and reviewed and approved the final manuscript. 
1. A 35-year old man's father was diagnosed with CRC at age 46 . He does not have any symptoms or any other risk factors for CRC himself. Which of the following is the current recommendation for CRC screening in him?

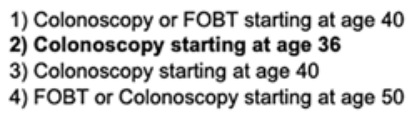

2. A 45-year-old woman is meeting with you to know when to begin CRC screening. She has neither symptoms, nor a personal or family history of cancer. You would recommend her:

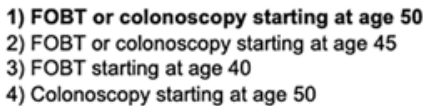

3. A 34-year-old man is referred to you for CRC screening advice. His maternal grandfather was diagnosed with CRC at age 61 a maternal uncle was also diagnosed with CRC at age 70. Your recommendation would be:

1) Colonoscopy starting at age 50

2) Colonoscopy starting at age 40

3) Colonoscopy starting at age 45

4) He should have started screening at age 25 , since you suspect he has Lynch syndrome

4. An 86-year-old man with no symptoms or family history of cancer comes to your office. He never underwent any CRC screening procedure. You recommend:

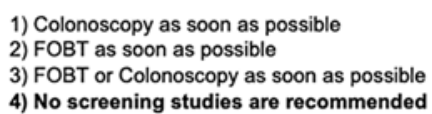

5. A 35-year-old man is meeting with you to know when to begin CRC screening. His mother was diagnosed with ovarian cancer at age 45, his maternal grandmother with pancreatic cancer at age 60 and a maternal uncle with CRC at age 50. Your recommendation is:

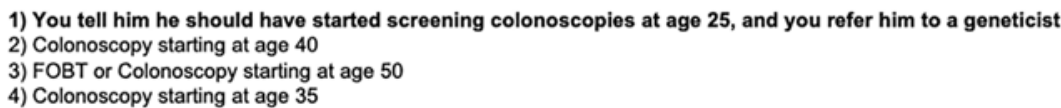

6. A 60-year old male underwent a screening colonoscopy. He had no symptoms or family history of cancer. The bowel preparation was excellent (Boston preparation $s c a l e=9$ ) and the examination was complete, with cecal intubation. A $6 \mathrm{~mm}$ tubular adenoma with high grade dysplasia was completely resected. What is the appropriate follow-up interval for colonoscopy for this patient?

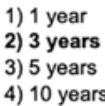

7. A 58-year old women with no family history of cancer undergoes a screening colonoscopy. The bowel preparation is noted as adequate and the examination was complete, with cecal intubation. A 7-mm sessile serrated polyp with no dysplasia was completely removed. When would you schedule the next colonoscopy?

$$
\begin{aligned}
& \text { 1. In } 1 \text { year } \\
& \text { 2. } \ln 3 \text { years } \\
& \text { 3. In } 5 \text { years } \\
& \text { 4. In } 10 \text { years }
\end{aligned}
$$

8. A 37-year old male underwent his first screening colonoscopy because his father was diagnosed with CRC at the age 47. The colonoscopy was complete, with cecal intubation and adequate bowel preparation. No colonic lesions were found during the examination. When would you schedule the next colonoscopy?

$$
\begin{aligned}
& \text { 1) In } 1 \text { year } \\
& \text { 2) In } 3 \text { years } \\
& \text { 3) In } 5 \text { years } \\
& \text { 4) In } 10 \text { years }
\end{aligned}
$$

9. A 60-year old male underwent a complete surveillance colonoscopy, with adequate bowel preparation. The finding was normal. In his immediately preceding colonoscopy performed three years ago, a $25 \mathrm{~mm}$-tubulovillous adenoma with high-grade dysplasia had been completely removed (en block resection). When would you schedule the next colonoscopy?

$$
\begin{aligned}
& \text { 1) In } 1 \text { year } \\
& \text { 2) In } 3 \text { years } \\
& \text { 3) In } 5 \text { years } \\
& \text { 4) In } 10 \text { years }
\end{aligned}
$$

10. A 49-year-old man underwent a screening colonoscopy. The examination was complete with cecal intubation and the bowel preparation was adequate (BPS 8/9). Two $12-\mathrm{mm}$ sessile serrated polyps without dysplasia were completely removed (en block resection) from the ascending colon. Three other 5-mm, sessile serrated polyps were completely resected from the transverse colon. When would you schedule the next colonoscopy?

$$
\begin{aligned}
& \text { 1) In } 6 \text { months } \\
& \text { 2) In } 1 \text { year } \\
& \text { 3) In } 3 \text { years } \\
& \text { 4) In } 5 \text { years }
\end{aligned}
$$

- Fig. 1 a CRC screening clinical vignettes used to test gastroenterology and coloproctology specialist performance according to current local guidelines. b Surveillance clinical vignettes used to test gastroenterology and coloproctology specialist performance according to current local guidelines. Boldface indicates the correct answer according to current local guideline. 


\section{Assessments}

Physician demographic data, including age, sex, specialty (gastroenterology or coloproctology), professional experience, location, place of work, and use of smartphone medical tools were assessed.

\section{Outcome measures}

To assess physician performance, the main outcome measure was the proportion of physicians correctly responding to at least $60 \%$ of the clinical scenarios, according to local current guidelines. Answers consistent with the current CRC screening and surveillance guidelines of the Instituto Nacional de Cáncer from Argentina [22] (INC) were considered accurate. The secondary outcome was the proportion of physicians correctly responding to at least $80 \%$ of the clinical vignettes. The proportion of physicians correctly responding to the clinical vignettes across their different categories'(screening and surveillance) were also analyzed.

Physician perception about the ease of the app's operation, as well as its usefulness in daily practice, was also assessed in the intervention group with a five-poiknt Likert scale questionnaire.

\section{CaPtyVa CRC app development}

The CaPtyVa Mobile app was custom developed with the support of ENDIBA and INC for the purpose of improving knowledge about CRC screening and surveillance and of increasing adherence to clinical practice guidelines among physicians. The app stores information about all the current local clinical practice guidelines related to CRC screening and surveillance, and through its decision-making algorithms, artificial intelligence assists physicians in the screening process recommendation. In the screening function, the app helps physicians to easily classify patients according to their individual CRC risk and to determine how and when to start screening tests ( $\mathbf{F i g . 2 a}$, > Fig. 2b, > Fig. 2c). In the surveillance function, the app assists physicians in determining when to repeat the next colonoscopy, according to guideline recommendations ( $\mathbf{F i g .} \mathbf{2} \mathbf{d}$, $\triangleright$ Fig. 2e, - Fig. 2f).

\section{Sample size calculation and statistical analysis}

Based on previous publications, the proportion of gastroenterologists responding to $100 \%$ of the clinical vignettes correctly was observed to be only $22 \%$ to $37 \%$ [21]. The study expert committee from the participating societies agreed that a minimum of $60 \%$ correct responses to the clinical vignettes was required to achieve acceptable guidelines adherence in daily practice. Based on a US survey [23], $60 \%$ of the gastroenterologists responded correctly to at least $60 \%$ of the clinical vignettes, and $31 \%$ to at least $80 \%$ of the vignettes. We hypothesized that the app would increase by, at least, $20 \%$ the proportion of physicians that responded correctly to $60 \%$ of the vignettes and estimated that 82 physicians in each group would provide the study with $80 \%$ power to detect a difference at a two-sided significance level of 0.05 . Considering a non-response rate of $35 \%, 250$ invitations were sent.
Statistical analysis was performed using STATA 13 (StataCorp. 2013. College Station, Texas, United States). A chi-square test, Fischer's exact test, student t-test, and correlation analysis were used whenever applicable. Logistic regression analysis was used to determine the characteristics associated with physician performance greater than $60 \%$.

\section{Results}

A total of 250 physicians were initially invited, of whom, 213 answered the invitation (85.2\%) and were included in the study and randomized $1: 1$ ton one of the two study groups ( $\triangleright$ Fig.3). The mean age of participants was 42.15 years \pm SD (9.74) with a mean time practicing in the specialty of 9.10 years. The majority of the participants were gastroenterologists (50\%) and $85.1 \%$ performed colonoscopies and $76.8 \%$ reported using smartphone medical tools in daily practice. There were no significant differences between the two groups regarding professional or demographic characteristics ( $>$ Table 1 ).

\section{Primary outcome}

The proportion of physicians who correctly responded to at least $60 \%$ of the clinical vignettes according to current local guidelines was significantly higher in the app group as compared to the control group ( $90 \%$ versus 56\%; RR1.6, $95 \%$ confidence interval $[\mathrm{Cl}]$ 1.34-1.9). Performance was also higher in the app group when analyzing both vignette categories: CRC screening (93\% versus $75 \%$; RR 1.24, $95 \% \mathrm{Cl} 1.01-1.40$ ) and surveillance ( $85 \%$ versus $47 \%$; RR $1.8095 \% \mathrm{Cl} 1.46-2.22$ ), respectively ( $\triangleright$ Table 2 ).

\section{Secondary outcome}

The proportion of physicians who correctly responded to at least $80 \%$ of the vignettes according to local current guidelines was also higher in the app group as compared to the control group (69\% versus 14\%; RR 4.85, 95\%Cl 3.03-7.78). Performance was also higher in the app group for both vignette categories: CRC screening (84.2\% versus $46.4 \%$; RR 1.81(1.462.25 ) and surveillance $(54.5 \%$ versus 9.82 ; RR $5.54,95 \% \mathrm{Cl}$ $3.08-9.99$ ), respectively ( $>$ Table 2 ).

The app group was superior to the control group for almost every clinical vignette. $>$ Fig. 4 summarizes the results for each clinical vignette comparing the performance of physicians in the CaPtyVa app group with those in the control group.

\section{Independent predictors of performance according to current local guidelines}

Time practicing in the specialty was the only significant independent predictor of correctly responding to at least $60 \%$ of the clinical vignettes according to current local guidelines. Physicians with more than 15 years of specialty practice were significantly less likely to achieve at least $60 \%$ correct answers (OR 0.37 [ $95 \% \mathrm{Cl} 0.18-0.70], P=0.003$ ) in the multivariate analysis. 


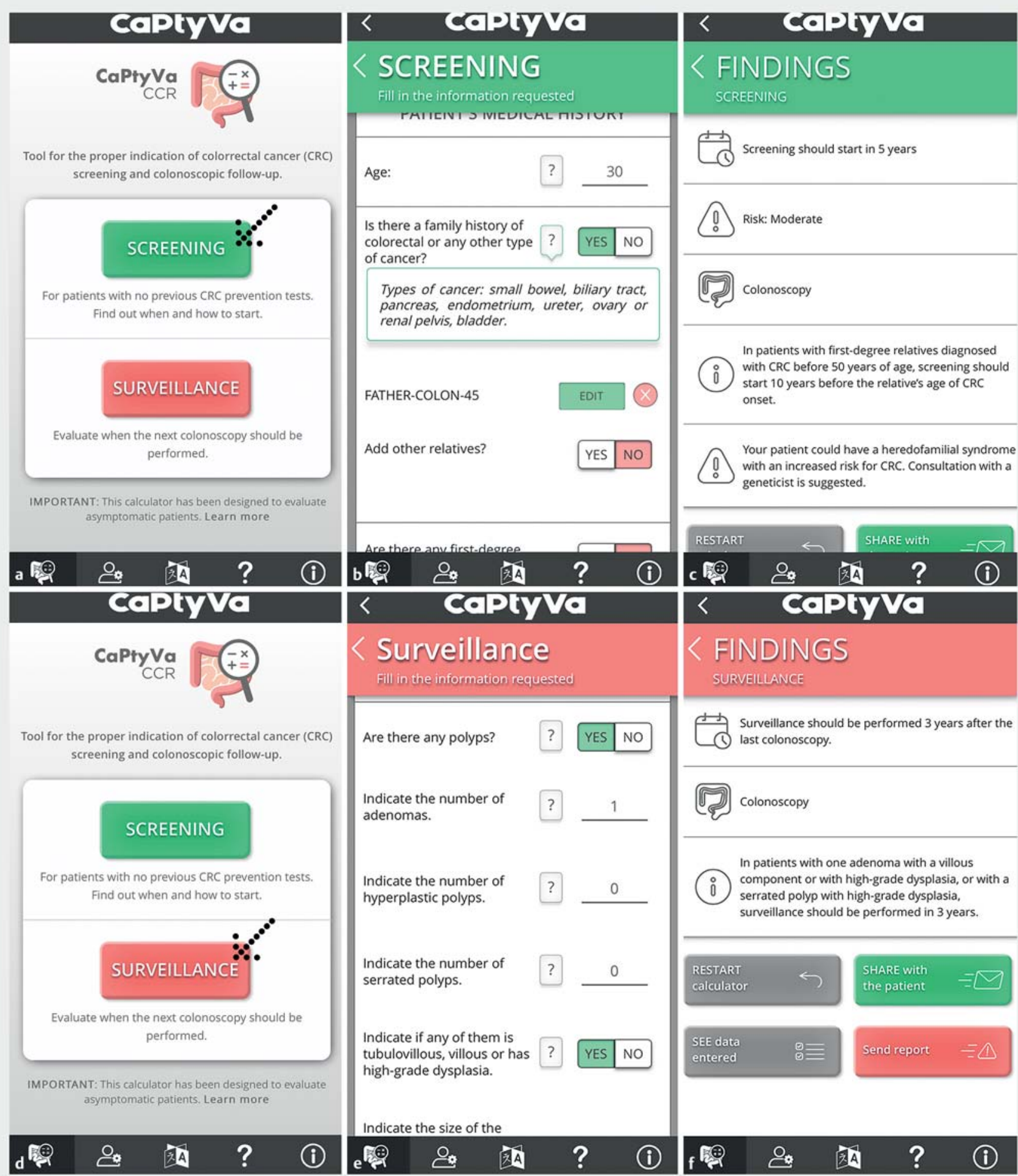

Fig. 2 a, b, c App screenshots showing the main menu, the screening function data loader, and the screening query results. $\mathbf{d}, \mathbf{e}, \mathbf{f}$ The main menu, the surveillance functios data loader, and the surveillance function query results.

\section{Physician perception about the app}

Regarding physician perception about the app, $96 \%$ of them agreed or strongly agreed (Likert scale: 4 and 5) that the app was easy to use, while only $4 \%$ of them strongly disagreed, dis- agreed or were neutral (Likert scale: 1, 2 and 3). On the other hand, $89 \%$ of the physicians agreed or strongly agreed (Likert scale: 4 and 5) that its implementation in daily practice could be of great use, and only $11 \%$ strongly disagreed, disagreed or were neutral (Likert scale: 1, 2 and 3) 


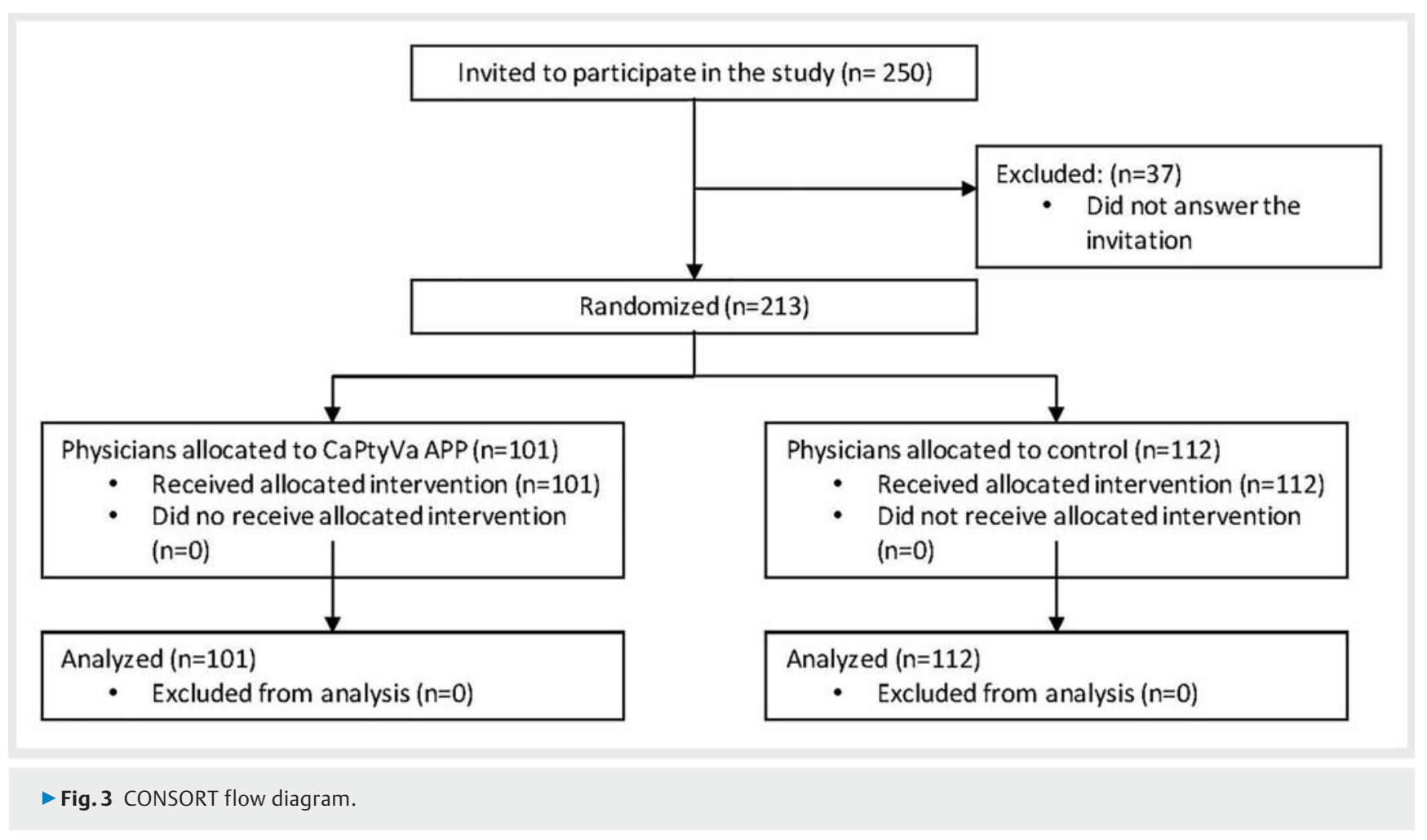

\section{Discussion}

To our knowledge, this is the first randomized controlled trial evaluating the efficacy of a MDSS for improving physician performance in responding to CRC screening and surveillance daily practice clinical scenarios. The present study shows that the utilization of a CRC screening MDSS by gastroenterology and colorectal surgeons improved their performance in responding to CRC screening and surveillance clinical scenarios based on guidelines. In addition, the app was perceived by most of the physicians as "easy to use" and as a tool of great utility in clinical practice.

Our study contributes several important pieces of information that add to understanding of the potential role of MDSSs in CRC screening clinical guideline implementation. First, this study documented substantial limitations in knowledge about and adherence to CRC screening and surveillance guidelines among gastroenterology and colorectal surgeons, an issue that needs to be addressed in order to optimize the allocation of resources to CRC screening policies. Only $56 \%$ of the specialists included in the control group of our study were able to correctly respond to at least $60 \%$ of the clinical scenarios with their current knowledge, while only $14 \%$ could respond to at least 80 $\%$ of them. These results are congruent with those reported in previous similar studies that also aimed to assess gastroenterologist guideline knowledge. A US national survey of 306 gastroenterologists using 12 clinical scenarios to test knowledge of both CRC screening and surveillance showed that only $60 \%$ of the physicians scored greater than $60 \%$, also highlighting a knowledge deficit [23]. In the largest US nationwide survey of 1432 gastroenterologists, Patell et al evaluated guideline knowledge using four clinical vignettes and correct identification of all factors used to determine screening policies, such as age to start or intervals of surveillance colonoscopy. This study also showed that only $22 \%$ of respondents were $100 \%$ accurate about screening and only $37 \%$ were $100 \%$ accurate about surveillance [21]. Thus, the poor specialist clinical practice guideline level of knowledge observed in our study is comparable to that observed in other studies and highlights the need for implementing new strategies to improve clinical practice guideline knowledge and adherence. In our study, the only factor independently associated with physician performance according to clinical practice guidelines was the number of years practicing in the specialty. In multivariate analysis, those with more than 15 years of practice were significantly less likely to respond correctly to at least $60 \%$ of questions This result is also congruent with previous studies that showed that more recent training among specialists was associated with a greater knowledge about and adherence to CRC screening guidelines [21], proving that the population included in our study is similar to those included in similar studies.

The primary outcome measure of our study was the proportion of physicians correctly responding to at least $60 \%$ of the clinical scenarios according to local current guidelines. This same outcome has also been used in previous studies to assess physician screening guideline knowledge and adherence. Guideline knowledge has been shown to be associated with better guideline recommendation adherence in clinical practice [24]. Therefore, the poor guideline knowledge observed in our study and in previous similar studies may reflect the reality of practice in the real world and may have important implications for healthcare expenditures. In addition to studies show- 
- Table 1 Characteristics of the physicians included in the study by group assignment.

\begin{tabular}{|c|c|c|c|c|c|c|}
\hline & \multicolumn{2}{|c|}{ app group } & \multicolumn{2}{|c|}{ Control group } & \multirow[b]{3}{*}{$\mathbf{P}$} & \multirow[b]{3}{*}{ Test } \\
\hline & \multicolumn{2}{|l|}{$n=101$} & \multicolumn{2}{|l|}{$n=112$} & & \\
\hline & $\mathbf{N}$ & $\%$ & $\mathbf{N}$ & $\%$ & & \\
\hline Age (yr, $\pm S D)$ & 42.40 & \pm 9.95 & 41.93 & \pm 9.59 & 0.73 & $t$-test \\
\hline \multicolumn{7}{|l|}{ Physician specialty } \\
\hline - Gastroenterology & 90 & 89.11 & 93 & 83.04 & \multirow[t]{2}{*}{0.24} & \multirow[t]{2}{*}{ Chi-square } \\
\hline - Coloproctology & 11 & 10.89 & 19 & 16.96 & & \\
\hline \multicolumn{7}{|l|}{ Time practicing the specialty } \\
\hline . $<5$ years & 31 & 30.69 & 36 & 32.14 & \multirow[t]{4}{*}{0.19} & \multirow[t]{4}{*}{ Chi-square } \\
\hline - 5-10 years & 21 & 20.79 & 31 & 27.68 & & \\
\hline - 10-15 years & 26 & 25.74 & 16 & 14.29 & & \\
\hline - >15 years & 33 & 22.77 & 29 & 25.89 & & \\
\hline Orders screening colonoscopy & 101 & 100 & 112 & 100 & 0.62 & \multirow[t]{2}{*}{ Chi-square } \\
\hline Performs colonoscopy & 90 & 89.11 & 94 & 83.93 & 0.28 & \\
\hline \multicolumn{7}{|l|}{ Current practice setting } \\
\hline - Public & 15 & 14.85 & 11 & 9.82 & \multirow[t]{3}{*}{0.33} & \multirow[t]{3}{*}{ Chi-square } \\
\hline - Private & 45 & 44.55 & 60 & 53.57 & & \\
\hline - Public and private & 41 & 40.59 & 41 & 36.61 & & \\
\hline Uses of any smartphone medical tool & 77 & 76.24 & 87 & 77.68 & 0.80 & Chi-square \\
\hline \multicolumn{7}{|l|}{ Place of residence } \\
\hline - Central Argentina & 65 & 64.36 & 78 & 69.64 & \multirow[t]{6}{*}{0.57} & \multirow[t]{6}{*}{ Chi-square } \\
\hline - South Argentina & 10 & 9.90 & 5 & 4.46 & & \\
\hline - West Argentina & 7 & 6.93 & 6 & 5.36 & & \\
\hline - Northwest Argentina & 8 & 7.92 & 11 & 9.82 & & \\
\hline - Northeast Argentina & 1 & 0.99 & 3 & 2.68 & & \\
\hline - Uruguay & 10 & 9.90 & 9 & 8.04 & & \\
\hline
\end{tabular}

SD, standard deviation.

Continuous variables are expressed as mean \pm SD. $P<0.05$ is considered statistically significant.

ing a low level of guideline knowledge, multiples studies reporting very high rates of screening colonoscopy overutilization and underutilization also have been published in the last decade. A recent meta-analysis published by Djinbachian et al that included 16 studies reporting on guidelines adherence for surveillance colonoscopy in different countries showed an adherence rate of only $48 \%(95 \% \mathrm{Cl} 37.3-60.4)$ [25]. This meta-analysis demonstrated a low worldwide adherence to surveillance colonoscopy guidelines, with an overall guideline adherence rate of less than $50 \%$. This lack of adherence to guidelines manifested through overutilization and underutilization in the above-mentioned study represents a clear example of how deviation from recommendations may threaten the effectiveness of CRC screening programs, as low-risk lesions or negative colonoscopies were assigned to shorter than recommended intervals, whereas in contrast, high-risk lesions were associated with delayed surveillance intervals. In fact, the consequences of these screening process failures have been demonstrated in a recent study by Doubeni et al, which showed that screening at inappropriate intervals or the failure to receive adequate-follow up for abnormal results significantly increased the risk for CRC death [21]. Based on all the above-mentioned studies, we consider that physician guideline knowledge and adherence is a determining factor for successfully implementing CRC screening programs. Although we are aware that there are many possible explanations for non-adherence to guidelines, such as disagreement with the guidelines, physician concerns about missed polyps, and perhaps financial reasons [26-29], the implementation of strategies that prove to to improve physician knowledge about clinical practice guidelines will have a positive impact on guideline adherence, and therefore, CRC screening effectiveness. 
- Table 2 Primary and secondary outcomes.

\begin{tabular}{|c|c|c|c|c|}
\hline Outcome & $\begin{array}{l}\text { App group } \\
(\mathrm{N}=101)\end{array}$ & $\begin{array}{l}\text { Control group } \\
(N=112)\end{array}$ & $\begin{array}{l}\text { Relative risk } \\
(95 \% \mathrm{Cl})\end{array}$ & $P$ value \\
\hline $\begin{array}{l}\text { Primary outcome-number (\%) } \\
\text { Physicians correctly responding to } \geq 60 \% \text { of the clinical vignettes } \\
\text { (CRC screening and surveillance) }\end{array}$ & $91(90.1)$ & $63(56.2)$ & $1.60(1.34-1.91)$ & $<0.001$ \\
\hline Physicians correctly responding to $\geq 60 \%$ of the screening clinical vignettes & $94(93.1)$ & $84(75.0)$ & $1.24(1.01-1.40)$ & $<0.001$ \\
\hline Physicians correctly responding to $\geq 60 \%$ of the surveillance clinical vignettes & $86(85.1)$ & $53(47.3)$ & $1.80(1.46-2.22)$ & $<0.001$ \\
\hline $\begin{array}{l}\text { Secondary outcome-number (\%) } \\
\text { Physicians correctly responding to } \geq 80 \% \text { of the clinical vignettes } \\
\text { (CRC screening and surveillance) }\end{array}$ & $70(69.3)$ & $16(14.3)$ & $4.85(3.03-7.78)$ & $<0.001$ \\
\hline Physicians correctly responding to $\geq 80 \%$ of the screening clinical vignettes & $85(84.2)$ & $52(46.4)$ & $1.81(1.46-2.25)$ & $<0.001$ \\
\hline Physicians correctly responding to $\geq 80 \%$ of the surveillance clinical vignettes & $55(54.5)$ & $11(9.82)$ & $5.54(3.08-9.99)$ & $<0.001$ \\
\hline
\end{tabular}

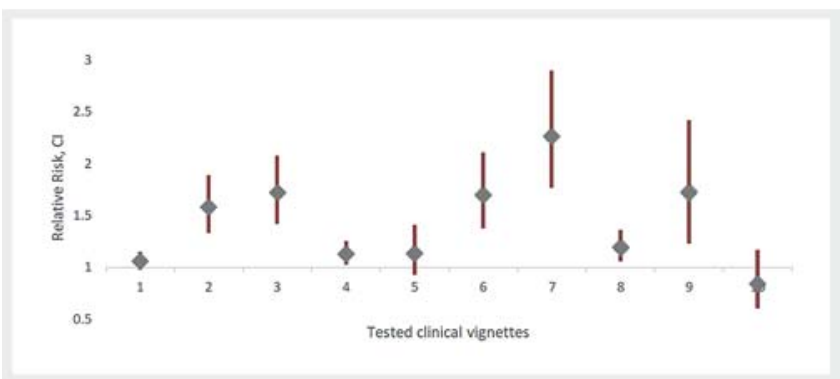

- Fig. 4 Physician performance (correct answers) in the app group compared with the control group for each clinical vignette. Results for each question are expressed as relative risks with their corresponding $95 \%$ confidence intervals $(\mathrm{Cls})$.

Our study shows that the use of a CRC screening MDSS is effective in improving the performance of specialists in responding correctly to both CRC screening and surveillance clinical daily practice scenarios, and it may, therefore, improve adherence. Physicians assigned to the app group had a higher probability of correctly resonding to at least $60 \%$ of the clinical vignettes as compared to controls ( $90 \%$ versus $56 \%$; RR1.6 Cl 1.341.91). The app group was also superior to the control group regarding secondary outcomes and in responding to both vignette categories - screening and surveillance. Various educational strategies have been employed in the past to improve knowledge of CRC screening, ranging from didactic lectures and guideline checklists, to an interactive case-based model [30-32]. However, these educational methods resulted in only a modest and variable improvement in knowledge. Their widespread implementation may require a significant effort and maintaining these educational strategies over time remains challenging. The technological evolution in smartphone mobile computing has given rise to the development of a new class of decision support systems, known as MDSS. These systems can be very beneficial for a wide range of different activities in which complex decisions are made under time pressure, decision-makers are on the move, and for which a large amount of constantly updated information need to be managed. Physician lack of time during a consultation adds to the large amount of complex and constantly updated information contained in CRC screening and surveillance guidelines, making MDSS an ideal resource for improving physician evidence-based decisionmaking about CRC screening. Using MDSS to guide clinical decision-making can increase standardization, which could have a positive impact on healthcare resource utilization, reduce risk of errors, eliminate unjustified variation in treatment, and increase patient safety. Because MDSS recommendations are the ones provided by clinical practice guidelines and are periodically updated when new information becomes available, the source documents and not the MDSS should be referred to as legal back-up whenever needed. The purpose of these kind of tools is to assist physicians in the clinical decision-making process and they should never replace clinical judgement.

Regarding the study design, a crossover study could have been an appropriate design for this research, based on the need for fewer participants than parallel trials to achieve sufficient power. Nevertheless, we chose not to use a crossover design because: 1) they usually take longer to complete, increasing the risk of attrition bias; and 2) we had some concerns about carryover effect and the adequate washout period to answer known clinical vignettes.

Our study does have certain limitations. First, although it was a binational study, only a particular study population participated (physicians who were smartphone users and who responded to the invitation to participate), which limits the generalizability of the results. Second, the main outcome measure was physician knowledge and not the actual adherence to guidelines in clinical practice. In addition, the clinical cases were based on a local guideline for CRC screening adopted in Argentina, which may differ slightly from other international guidelines. 


\section{Conclusions}

In conclusion, our study demonstrated that a MDSS is an effective tool to improve the ability of colorectal surgeons and gastroenterologists to respond correctly to CRC screening and surveillance scenarios seen in daily clinical practice. This dedicated mobile app was shown to be user-friendly and potentially useful in clinical practice. Digital resources may help physicians to make evidence-based decisions about CRC screening, improving its effectiveness.

\section{Competing interests}

The authors declare that they have no conflict of interest.

\section{References}

[1] Grimshaw J, Thomas R, MacLennan G et al. Effectiveness and efficiency of guideline dissemination and implementation strategies. Health Technol Assess 2004: 61-72

[2] Lugtenberg M, Burgers ], Westert G. Effects of evidence-based clinical practice guidelines on quality of care: a systematic review. Qual Saf Health Care 2009; 18: 385-392

[3] Gagliardi A, Alhabib S. Members of Guidelines International Network Implementation Working Group. Trends in guideline implementation: a scoping systematic review. Implement Sci 2015; 21: 54

[4] Durieux P, Nizard R, Philippe R et al. A clinical Decision Support System for prevention of venous thromboembolism. JAMA 2000; 7: $2816-2828$

[5] Hunt DL, Haynes RB, Hanna SE et al. Effects of computer-based clinical decision support systems on physician performance and patient outcome: a systematic review. JAMA 1998; 280: 1339-1346

[6] McGlynn EA, Asch SM, Adams ] et al. The quality of health care delivered to adults in the United States. N Engl J Med 2003; 348: 26352645

[7] Kohn LT, Corrigan JM, Donalson MS et al. To err is human: building a safer health system. Washington, DC: National Academy Press; 1999

[8] Vincent C, Neale G, Woloshynowych M et al. Adverse events in British hospitals: preliminary retrospective record review. BM] 2001; 322: 517-519

[9] Hunt DL, Haynes RB, Hanna SE et al. Effects of computer-based clinical decision support systems on physician performance and patient outcomes: a systematic review. JAMA 1998; 280: 1339-1346

[10] Bennett JW, Glasziou PP. Computerised reminders and feedback in medication management: a systematic review of randomised controlled trials. Med J Aust 2003; 178: 217-222

[11] Walton RT, Harvey E, Dovey $S$ et al. Computerised advice on drug dosage to improve prescribing practice. Cochrane Database Syst Rev 2001; 1: CD002894

[12] Walton R, Dovey S, Harvey E et al. Computer support for determining drug dose: systematic review and meta-analysis. BMJ 1999; 318: 984990

[13] Kaushal R, Shojania KG, Bates DW. Effects of computerized physician order entry and clinical decision support systems on medication safety: a systematic review. Arch Intern Med 2003; 163: 1409-1416
[14] Bates DW, Teich JM, Lee J et al. The impact of computerized physician order entry on medication error prevention. J Am Med Inform Assoc 1999; 6: 313-321

[15] Shea S, DuMouchel W, Bahamonde L. A meta-analysis of 16 randomized controlled trials to evaluate computer-based clinical reminder systems for preventive care in the ambulatory setting. J Am Med Inform Assoc 1996; 3: 399-409

[16] Bates DW, Teich JM, Lee J et al. The impact of computerized physician order entry on medication error prevention. J Am Med Inform Assoc 1999; 6: 313-321

[17] Hulscher ME, Wensing M, van der Weijden $T$ et al. Interventions to implement prevention in primary care. Cochrane Database Syst Rev 2001; 1: CD000362

[18] Oxman AD, Thomson MA, Davis DA et al. No magic bullets: a systematic review of 102 trials of interventions to improve professional practice. CMAJ 1995; 153: 1423-1431

[19] Bray F, Ferlay J, Soerjomataram I et al. Global Cancer Statistics 2018: GLOBOCAN Estimates of Incidence and Mortality Worldwide for 36 Cancers in 185 Countries. CA Cancer J Clin 2018; 68: 394-424

[20] Doubeni C, Fedewa S, Levin T et al. Modifiable failures in the colorectal cancer screening process and their association with risk of death. Gastroenterology 2019; 156: 63-67

[21] Patell R, Karwa A, Lopez R et al. Poor knowledge of colorectal cancer screening and surveillance guidelines in a national cohort of digestive disease specialists. Dig Dis Sci 2019; 64: 391-400

[22] Instituto Nacional del Cáncer. Ministerio de Salud de La Nación. Cáncer colorrectal en la Argentina. Organización, cobertura y calidad de las acciones de prevención y control. Informe final de diciembre de 2011; diagnóstico de situación de la Argentina: 2013.

[23] Iskandar H, Yan Y, Elwing J et al. Predictors of poor adherence of US gastroenterologists with colonoscopy screening and surveillance guidelines. Dig Dis Sci 2015; 60: 971-978

[24] Patel N, Tong L, Ahn C et al. Post-polypectomy guideline adherence: importance of belief in guidelines, not guideline Knowledge or fear of missed cancer. Dig Dis Sci 2015; 60: 2937-2945

[25] Djinbachian R, Dubé AJ, Durand M et al. Adherence to post-polypectomy surveillance guidelines: a systematic review and meta-analysis. Endoscopy 2019; 51: 673-683

[26] Kawamoto K, Houlihan CA, Balas D et al. Improving clinical practice using clinical decision support systems: a systematic review of trials to identify features critical to success. BMJ 2005; 330: 765

[27] Mandelblatt JS, Yabroff KR. Effectiveness of interventions designed to increase mammography use: a meta-analysis of provider-targeted strategies. Cancer Epidemiol Biomarkers Prev 1999; 8: 759-767

[28] Wendt T, Knaup-Gregori P, Winter A et al. Decision support in medicine: a survey of problems of user acceptance. Stud Health Technol Inform 2000; 77: 852-856

[29] Sim I, Gorman P, Greenes RA et al. Clinical decision support systems for the practice of evidence-based medicine. J Am Med Inform Assoc 2001; 8: 527-534

[30] Solberg LI, Brekke ML, Fazio C] et al. Lessons from experienced guideline implementers: attend to many factors and use multiple strategies. Jt Comm J Qual Improv 2000; 26: 171-188

[31] Lane DS, Messina CR, Cavanagh MF et al. A provider intervention to improve colorectal cancer screening in county health centers. Med Care 2008; 46: S109-S116

[32] Schroy PC, Glick JT, Geller AC et al. A novel educational strategy to enhance internal medicine residents' familial colorectal cancer knowledge and risk assessment skills. Am J Gastroenterol 2005; 100: 677-684 